\title{
Calls to the British Columbia Drug and Poison Information Centre: A summary of differences by health service areas
}

\author{
Kathleen E McLean ${ }^{1}$, Sarah B Henderson ${ }^{1,3}$, Debra Kent ${ }^{2}$, Tom Kosatsky ${ }^{1}$ \\ 1. Environmental Health Services, BC Centre for Disease Control, Vancouver BC Canada \\ 2. BC Drug and Poison Information Centre, BC Centre for Disease Control, Vancouver BC Canada \\ 3. School of Population and Public Health, University of British Columbia, Vancouver BC Canada
}

\begin{abstract}
Objectives: Poison control centres provide information on the management of poisoning incidents. The British Columbia (BC) Drug and Poison Information Centre recently implemented an electronic database system for recording case information, making it easier to use case data as a potential source of population-based information on health services usage and health status. This descriptive analysis maps poisoning case rates in $\mathrm{BC}$, highlighting differences in patient age, substance type, medical outcome, and caller location.

Methods: There were 50,621 human exposure cases recorded during 2012 and 2013. Postal code or city name was used to assign each case to a Health Service Delivery Area (HSDA). Case rates per 1,000 person-years were calculated, including crude rates, age-standardized rates, age-specific rates, and rates by substance type, medical outcome, and caller location.

Results: The lowest case rate was observed in Richmond, a city where many residents do not speak English as a first language. The highest rate was observed in the Northwest region, where the economy is driven by resource extraction. Pharmaceutical exposures were elevated in the sparsely populated northern and eastern areas. Calls from health care facilities were highest in the Northwest region, where there are many remote Aboriginal communities.

Conclusions: Case rates were generally highest in the primarily rural northern and eastern areas of the province. Considering these results alongside contextual factors informs further investigation and action: addressing cultural and language barriers to accessing poison centre services, and developing a public health surveillance system for severe poisoning events in rural and remote communities.

Keywords: Poison Control Centers; British Columbia; Geographic Mapping.

Abbreviations: British Columbia (BC), Health Service Delivery Area (HSDA), Poison control centre (PCC), Drug and Poison Information Centre (DPIC), United States (US), Visual Dotlab Enterprises (VDLE).

Correspondence: kathleen.mclean@bccdc.ca

DOI: 10.5210/ojphi.v6i2.5376

Copyright @2014 the author(s)

This is an Open Access article. Authors own copyright of their articles appearing in the Online Journal of Public Health Informatics. Readers may copy articles without permission of the copyright owner(s), as long as the author and OJPHI are acknowledged in the copy and the copy is used for educational, not-for-profit purposes.
\end{abstract}




\section{Introduction}

British Columbia (BC) is Canada's westernmost province, covering almost one million square kilometres, and containing 9.5\% of Canada's total land and freshwater area [1]. The province has a wide range of geographic regions including coastal, mountain, temperate rainforest, semi-arid desert, and boreal forest. In 2011, $60.4 \%$ of the 4.4 million residents lived in metropolitan Vancouver and Victoria in the southern coastal region (Figure 1) [2]. The rest of the population is distributed throughout the vast remainder of the province in smaller centres, and in rural and remote communities. The population is ethnically diverse, with $24.8 \%$ identifying as visible minorities (the highest percentage of all Canadian provinces and territories) [3], and 4.8\% identifying as Aboriginal [4].

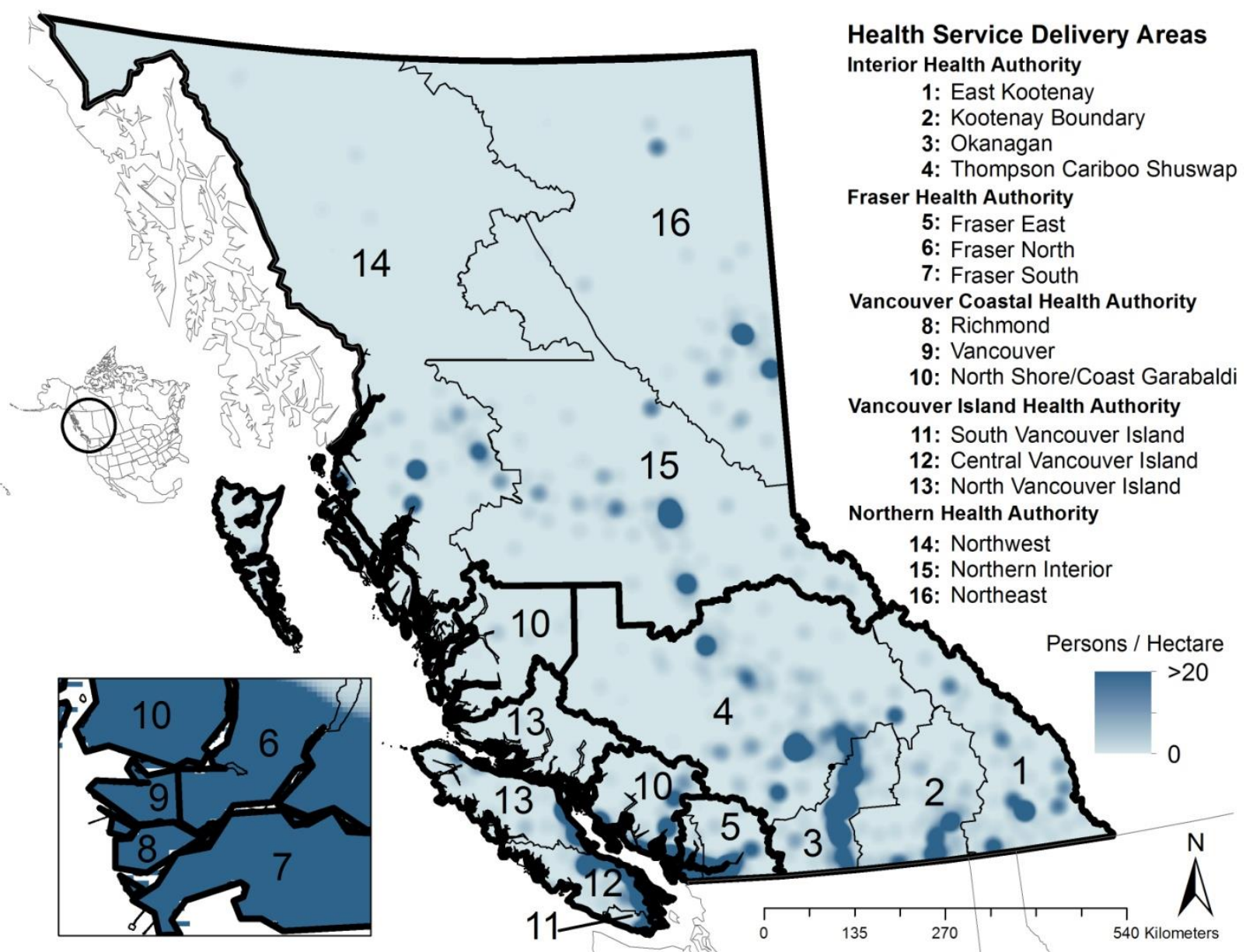

Figure 1: Population Density and Health Service Delivery Areas in British Columbia (Population density data for 2011, visualized using ArcGIS 10.)

Health care is publicly funded in BC, and is governed by the BC Ministry of Health via six independent health authorities. The Provincial Health Services Authority oversees province-wide programs and services, and five regional health authorities serve specific geographic areas (Figure 1). The Vancouver Coastal Health Authority includes the municipalities of Vancouver, Richmond, North Vancouver and West Vancouver. It is characterized by an ethnically diverse population with a comparatively high percentage of adults in the 20-39 age range (Table 1), and 
an economy dominated by the financial and service sectors. The Fraser Health Authority includes several commuter suburbs near Vancouver, as well as rural communities heavily engaged in dairy, poultry, and berry agriculture. Fraser Health has the largest population on the smallest land area of all the health authorities [5], including diverse ethnic and Aboriginal groups and a high percentage of children (Table 1). The Vancouver Island Health Authority and the Interior Health Authority are retirement destinations with larger populations of older adults and seniors. Services, tourism and forestry are common to the economies of both, while Interior Health also relies on coal, mining, agriculture, and hydroelectric production. The economy in the Northern Health Authority is predominantly resource-based, including forestry, mining, oil and gas exploration and production, agriculture, hydroelectric production, and tourism. There are many Aboriginal communities in the Northern Health Authority, and it has the highest percentage of children 19 years and under in the province.

Table 1: Average population counts and age distributions by Health Service Delivery Area for 2012 and 2013

\begin{tabular}{|c|c|c|c|c|c|c|c|}
\hline Health Service Delivery Area & $\begin{array}{l}\text { Total } \\
\text { Population }\end{array}$ & $\begin{array}{l}<=5 \\
\text { years } \\
(\%)\end{array}$ & $\begin{array}{l}6-12 \\
\text { years } \\
(\%)\end{array}$ & \begin{tabular}{|l|}
$13-19$ \\
years \\
$(\%)$
\end{tabular} & $\begin{array}{l}20-39 \\
\text { years } \\
(\%)\end{array}$ & $\begin{array}{l}40-69 \\
\text { years } \\
(\%)\end{array}$ & $\begin{array}{l}70+ \\
\text { years } \\
(\%)\end{array}$ \\
\hline East Kootenay (\#1) & 76284 & 6.2 & 7.0 & 7.9 & 21.8 & 44.5 & 12.6 \\
\hline Kootenay Boundary (\#2) & 77154 & 5.2 & 6.8 & 7.8 & 20.4 & 46.2 & 13.5 \\
\hline Okanagan (\#3) & 347214 & 5.2 & 6.5 & 8.0 & 22.1 & 42.4 & 15.8 \\
\hline Thompson Cariboo Shuswap (\#4) & 217689 & 5.6 & 6.8 & 8.3 & 22.4 & 44.2 & 12.7 \\
\hline Fraser East (\#5) & 286202 & 7.2 & 8.4 & 9.4 & 26.1 & 38.0 & 10.8 \\
\hline Fraser North (\#6) & 632749 & 6.0 & 6.8 & 8.5 & 29.3 & 40.7 & 8.7 \\
\hline Fraser South (\#7) & 759100 & 6.8 & 8.2 & 9.6 & 27.2 & 39.0 & 9.1 \\
\hline Richmond (\#8) & 200029 & 5.3 & 6.6 & 8.7 & 27.7 & 42.4 & 9.4 \\
\hline Vancouver (\#9) & 652513 & 4.8 & 5.2 & 6.5 & 35.2 & 38.7 & 9.6 \\
\hline North Shore/Coast Garibaldi (\#10) & 279488 & 5.5 & 7.2 & 8.6 & 23.4 & 43.3 & 11.9 \\
\hline South Vancouver Island (\#11) & 369820 & 5.0 & 5.8 & 7.3 & 26.6 & 41.8 & 13.3 \\
\hline Central Vancouver Island (\#12) & 261936 & 5.2 & 6.3 & 7.8 & 20.3 & 44.8 & 15.4 \\
\hline North Vancouver Island (\#13) & 119096 & 5.6 & 6.8 & 8.2 & 20.0 & 46.2 & 13.1 \\
\hline Northwest (\#14) & 72848 & 7.1 & 8.9 & 10.1 & 24.1 & 41.9 & 8.0 \\
\hline Northern Interior (\#15) & 141765 & 7.0 & 8.0 & 9.6 & 25.4 & 41.8 & 8.3 \\
\hline Northeast (\#16) & 68758 & 8.9 & 9.1 & 9.6 & 31.0 & 35.4 & 6.2 \\
\hline
\end{tabular}

Given its vast geography and diverse population, it is important to evaluate whether health services reach everyone in BC. The 16 Health Service Delivery Areas (HSDAs) nested within the regional health authorities provide an ideal geographic unit for assessing spatial differences (Figure 1). Previous work has used days in hospital, physician billings, and pharmaceutical records to assess use of health services, showing considerable disparity across the HSDAs [5]. For example, the Northern Health Authority had the highest rates of acute hospital care and Online Journal of Public Health Informatics * ISSN 1947-2579 * http://ojphi.org * 6(2):e179, 2014 
general physician billings, but the lowest rate of specialist physician billings and the smallest percentage of high-demand health care users [5]. This type of spatial information is valuable for retrospective evaluation of health services and status, and for prospective planning to support improved access and delivery.

Poison control centres (PCCs) provide information to the general public and healthcare professionals on the management of poisoning incidents, resulting in health care savings and improved outcomes. Access to PCCs can reduce hospitalizations and emergency room visits [6], and the length of hospital stays [7,8]. A recent economic review found health care savings of up to eight dollars for every dollar spent on PCCs [9]. The BC Drug and Poison Information Centre (DPIC) was established in 1975 as one of the first PCCs in Canada, and is currently operated by the BC Centre for Disease Control, an agency of the Provincial Health Services Authority. Current programs include a 24-hour toll-free poison information service for the entire province and a separate toll-free drug information consultation service for healthcare professionals. In October 2011, DPIC implemented a system for recording case information using an electronic database called Visual Dotlab Enterprises (VDLE). Previously, DPIC used paper records and limited data were entered for routine reporting. The new system offers many benefits, including access to all case data in near-real-time.

When a client calls about a suspected poisoning, the responding DPIC specialist (a pharmacist or nurse) records information about the patient, the exposure, evident symptoms, and pertinent context. After assessing the situation and potential toxicity, the DPIC specialist provides treatment advice. This may include the recommendation to stay at home with follow-up from DPIC if necessary, or it may involve referral to the hospital with additional consultations as needed. In emergency situations, the DPIC specialist helps coordinate transport to the hospital, and informs the emergency department of the situation and treatment recommendations. During a call, the highest priority is obtaining information essential for managing the poisoning incident, so non-essential information is usually collected at the end. Thus, data may be incomplete if the caller ends the call early, or if other circumstances make it difficult to request non-essential information.

Data from PCCs are a potential source of population-based information on health services usage and health status. Several epidemiologic studies have used data from PCCs to investigate specific outcomes such as suicide attempts [10], or specific exposures such as pharmaceuticals [11,12], inhalants [13], and pesticides [14-17]. Data from PCCs are also used for public health surveillance in the United States (US) and Europe, but not yet in Canada [18]. In the US, the American Association of Poison Control Centers and the Centers for Disease Control and Prevention have implemented a national surveillance system called the National Poison Data System. This system automatically aggregates and analyzes data from US poison centers, issuing alerts if anomalies are detected in total call volume, call volume by clinical effect, or for certain defined cases [19]. The VDLE software used by DPIC conforms with the same data guidelines. Although PCC data have proven valuable for evaluating surveillance questions, few studies have leveraged spatial information to assess differences between populations [12,14,17]. Until the implementation of VDLE, there was no simple, systematic way to map spatial differences in the use of DPIC services. This study is the first descriptive analysis of DPIC cases in the new database, providing current information about DPIC operations, and baseline information for more specific studies in future. The primary objective was to map poisoning case rates by 
HSDA, and to highlight differences in patient age, substance types, medical outcome, and caller location.

\section{Methods}

There were 61,131 cases recorded in the DPIC database between January 1, 2012 and December 31,2013 . Of these, 2,758 were calls to the drug information service for healthcare professionals. The remaining 58,373 were related to poisonings, with 50,621 (86.7\%) human exposures, 1,688 (2.9\%) animal exposures, and 6,064 (10.4\%) information-only calls (Figure 2). This work focuses on the human exposure cases. Population estimates for 2012 and 2013 from BC Stats [20] were used to calculate age-standardized and age-specific case rates. Patient age was unknown for 9,748 (19.3\%) cases.

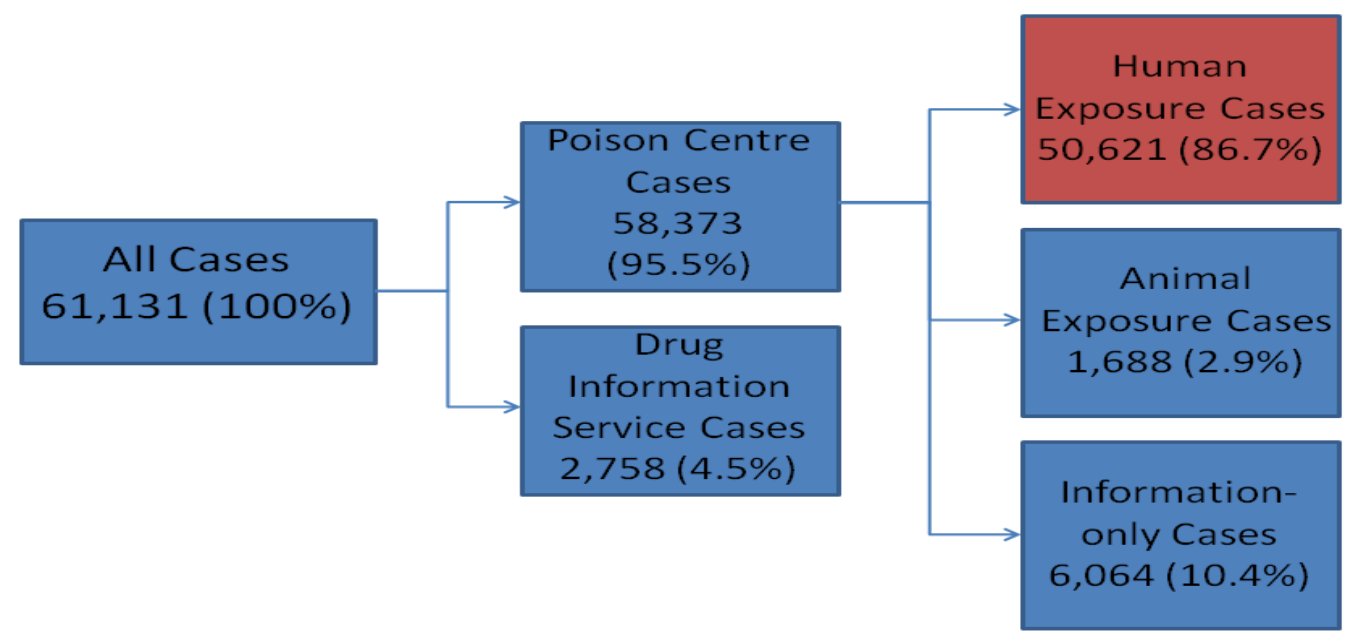

Figure 2: Cases recorded in the DPIC database between January 1, 2012 and December 31,2013 , showing those selected for analysis in red

To obtain geographic information, DPIC specialists ask for the caller's city name and/or postal code. If the DPIC specialist enters a postal code into VDLE, the city field is auto-populated with the appropriate city. If only a city name is entered, VDLE automatically assigns the first available 6-digit postal code as the default for that city unless the DPIC specialist enters a code specifying that the postal code is unknown. The 50,621 exposures included 13,441 urban and 551 rural postal codes that were merged with a comprehensive postal code database and assigned to HSDAs. Cases with no postal code were matched to an HSDA by the city name, if provided, using a database of $\mathrm{BC}$ communities and health regions. In total, 49,613 exposure cases (98.0\%) were matched to an HSDA and the remainder were excluded from the spatial analyses. All further data analysis and visualization was conducted in R 3.0.2 [21]. Case counts by call type and age were then aggregated by HSDA.

Crude human exposure case rates per 1,000 person-years were calculated using all available data for 2012 and 2013. Directly age-standardized case rates were calculated after removing cases with unknown age. Confidence intervals for standardized case rates were calculated using a Online Journal of Public Health Informatics * ISSN 1947-2579 * http://ojphi.org * 6(2):e179, 2014 
method by Fay and Feuer (1997) that approximates exact confidence intervals [22]. For all other rates, $95 \%$ confidence intervals were calculated as follows:

Confidence Interval $=(1000$ person-years $/ \mathrm{n}) *(\mathrm{~d}+/-(1.96 * \sqrt{\mathrm{d}}))$,

where $\mathrm{n}$ is the population of the region and $\mathrm{d}$ is the number of cases upon which the rate is based. To compare rates and other measures from different regions in the maps, Z-scores were calculated as follows:

$\mathrm{Z}_{\mathrm{i}}=\left(\mathrm{m}_{\mathrm{i}}-\mathrm{mu}\right) / \mathrm{SD}$,

where $\mathrm{i}$ is the HSDA region $(1,2, \ldots 16), \mathrm{m}$ is the measure of interest, $\mathrm{mu}$ is the mean of the measure of interest for all regions, and SD is the standard deviation of the measure of interest for all regions.

Human exposure cases were categorized as pharmaceutical or non-pharmaceutical based on the primary substance involved. DPIC specialists rank substances based on the relative contribution of each to the observed clinical effects [23]. Categorization of the substances occurs in VDLE following the US National Poison Data System guidelines. Cases were also categorized by medical outcome, classified as mild or severe for these analyses. The medical outcome is determined by the DPIC responder at the conclusion of a case. Mild outcomes included the following categories: no effect; minor effect; not followed - judged as nontoxic exposure (clinical effects not expected); not followed - minimal clinical effects possible (no more than minor effect(s) possible); unrelated effect - the exposure was probably not responsible for the effect(s); and confirmed non-exposure. Severe outcomes included the following categories: moderate effect; major effect; death; and death - indirect report. Finally, cases were categorized by the site of the caller. Most calls come from a private residence, healthcare facility, or workplace. Calls from a public area, school, restaurant, or other site were classified as 'other'.

\section{Results}

\section{Age-adjusted case rates}

The crude human exposure case rate per 1,000 person-years for 2012-2013 ranged across the HSDAs from 2.6 in the municipality of Richmond (HSDA \#8) to 8.7 in the Northwest (\#14). The province-wide crude rate over that same time period was 5.4 cases per 1,000 person-years. Ageadjusted rates were lowest in Richmond at 2.2 and highest in the Northwest and East Kootenay (\#1) at 6.4 cases per 1,000 person-years (Table 2).

\section{Age-Specific Rates}

Age-specific case rates (Figure 3) were expressed as Z-scores for children 5 years of age and under, children 6-12 years, teens 13-19 years, adults 20-39 years, adults 40-69 years, and seniors 70 years or older. Province-wide case rates for these age categories were 40.0, 3.6, 4.2, 2.3, 1.4, and 2.1 cases per 1,000 person-years, respectively. The highest Z-scores for these age groups were 1.08 in East Kootenay (\#1), 1.72 in North Vancouver Island (\#13), 2.04 in the Northern Interior (\#15), 2.24 in the Northwest (\#14), 2.56 in the Northwest, and 1.95 in East Kootenay, respectively. The lowest Z-scores were in Richmond (\#8) for all age categories. Rates, confidence intervals, and Z-scores for each HSDA are included in the supplemental material (Table S1A and S1B). 
Table 2: Crude and Adjusted Human Exposure Case Rates per 1,000 person-years for 2012-2013 by Health Service Delivery Area

\begin{tabular}{|l|l|l|l|l|l|}
\hline Health Service Delivery Area & $\begin{array}{l}\text { Human } \\
\text { Exposure } \\
\text { Cases }\end{array}$ & $\begin{array}{l}\text { Crude } \\
\text { Case } \\
\text { Rate }\end{array}$ & $\begin{array}{l}\text { 95\% } \\
\text { Confidence } \\
\text { Interval } \\
\text { (Lower, } \\
\text { Upper) }\end{array}$ & $\begin{array}{l}\text { Age- } \\
\text { Adjusted } \\
\text { Case } \\
\text { Rate }\end{array}$ & $\begin{array}{l}\text { 95\% } \\
\text { Confidence } \\
\text { Interval } \\
\text { (Lower, } \\
\text { Upper) }\end{array}$ \\
\hline East Kootenay (\#1) & 1170 & 7.7 & $7.2,8.1$ & 6.4 & $6.0,6.8$ \\
\hline Kootenay Boundary (\#2) & 1055 & 6.8 & $6.4,7.2$ & 6.0 & $5.6,6.4$ \\
\hline Okanagan (\#3) & 3821 & 5.5 & $5.3,5.7$ & 4.8 & $4.7,5.0$ \\
\hline Thompson Cariboo Shuswap (\#4) & 2923 & 6.7 & $6.5,7.0$ & 5.6 & $5.4,5.8$ \\
\hline Fraser East (\#5) & 3894 & 6.8 & $6.6,7.0$ & 5.0 & $4.8,5.2$ \\
\hline Fraser North (\#6) & 6098 & 4.8 & $4.7,4.9$ & 3.8 & $3.7,3.9$ \\
\hline Fraser South (\#7) & 6891 & 4.5 & $4.4,4.6$ & 3.4 & $3.3,3.5$ \\
\hline Richmond (\#8) & 1050 & 2.6 & $2.5,2.8$ & 2.2 & $2.0,2.3$ \\
\hline Vancouver (\#9) & 6583 & 5.0 & $4.9,5.2$ & 3.9 & $3.8,4.1$ \\
\hline North Shore/Coast Garibaldi (\#10) & 2766 & 4.9 & $4.8,5.1$ & 4.1 & $3.9,4.3$ \\
\hline South Vancouver Island (\#11) & 4118 & 5.6 & $5.4,5.7$ & 4.8 & $4.6,5.0$ \\
\hline Central Vancouver Island (\#12) & 3191 & 6.1 & $5.9,6.3$ & 5.4 & $5.2,5.6$ \\
\hline North Vancouver Island (\#13) & 1549 & 6.5 & $6.2,6.8$ & 5.5 & $5.2,5.8$ \\
\hline Northwest (\#14) & 1266 & 8.7 & $8.2,9.2$ & 6.4 & $6.0,6.9$ \\
\hline Northern Interior (\#15) & 2153 & 7.6 & $7.3,7.9$ & 5.8 & $5.6,6.1$ \\
\hline Northeast (\#16) & 1085 & 7.9 & $7.4,8.4$ & 5.2 & $4.8,5.5$ \\
\hline
\end{tabular}

\section{Other categorizations}

There were 22,916 pharmaceutical (e.g. analgesics, muscle relaxants, and street drugs [23]) and 28,489 non-pharmaceutical (e.g. adhesives, tobacco, and cleaning products [23]) exposures during 2012-2013. To compare across the HSDAs, we examined pharmaceutical exposures as a percentage of all exposure cases (Figure 4). The East Kootenay, Northwest, and Northeast (\#16) regions had percentages of pharmaceutical exposure cases that were significantly higher than the provincial average with Z-scores of 1.46, 1.70, and 1.61, respectively. The percentage of pharmaceutical exposure cases was significantly lower than the provincial average in Kootenay Boundary (\#2) and South Vancouver Island (\#11). Rates, confidence intervals, and Z-scores for each HSDA are included in the supplemental material (Table S2).

There were 41,867 cases with mild outcomes and 8,754 severe cases. We used the percentage of all exposure cases with a severe outcome to compare across the HSDAs (Figure 4). Northwest and Vancouver (\#9) had more severe outcomes, with Z-scores greater than 1.0, whereas South 
Vancouver Island had fewer severe outcomes. Rates, confidence intervals, and Z-scores for each HSDA are included in the supplemental material (Table S3).

Of the 49,613 exposure cases, 30,525 (61.5\%) calls were from a residence, 7,490 (15.1\%) were from a health care facility, $640(1.3 \%)$ were from a workplace, and 10,947 (22.1\%) were from a site classified as 'other'. Northwest had the lowest percentage of calls from a residence (48.0\%) and the highest percentage of calls from a health care facility (32.7\%) (Figure 5). South and Central Vancouver Island (\#11 and \#12, respectively) had the highest percentages of calls from a residence $(67.8 \%$ and $65.5 \%$, respectively), and among the lowest percentages of calls from a health care facility (7.4\% and $11.8 \%$, respectively). Vancouver and Richmond had the highest percentages of calls from a workplace at $2.3 \%$ and $1.7 \%$, respectively, while some of the more heavily industrialized HSDAs such as East Kootenay and Northeast had the among the lowest percentages $(0.7 \%$ and $0.9 \%$, respectively).

\section{Discussion}

After 35 years of operation, this is the first time that calls to DPIC have been mapped across BC. The province-wide crude human exposure case rate was 5.4 per 1,000 person-years for 20122013 and the regional rates ranged from 2.6 to 8.7. These were slightly lower than corresponding non-standardized rates at 52 US poison centres in 2001, which ranged from 4.8 to 17.1 cases per 1,000 person-years [24], with a mean of 8.1 cases per 1,000 population in 2001 and 7.2 in 2012 [25]. Our results showing lower rates in the predominantly urban HSDAs of Vancouver, Richmond, and Fraser South compared with the predominantly rural HSDAs in the north and east of the province highlight the need for this kind of analysis. In particular, Richmond had consistently lower rates than other HSDAs. One possible explanation is language and/or cultural barriers to accessing DPIC services. In 2006, 61\% of residents in Richmond spoke a language other than English or French as their first language, the highest of all BC HSDAs [26]. In addition, 37\% of Richmond residents in 2006 were immigrants who landed in Canada after 1990, compared with $13 \%$ for the entire province [26]. DPIC currently offers service in languages other than English, but it did not prior to 2013.

A challenge with interpreting case rates from PCC data is assessing the extent to which rates reflect true poisoning incidence rather than PCC awareness and use [24], but previous studies suggest that our results reflect true regional differences. Regional variation in standardized mortality ratios and rates of hospital separations (deaths and discharges) for unintentional injuries have been shown among children and youth [27] and adults and seniors [28], with rural health regions tending to have higher rates than urban regions. A more recent study reported that the Northern Health Authority had the highest age standardized rate for poisoning-related hospitalizations in BC from February 2001 to June 2005, but the lowest age standardized poisoning mortality rate from 2000 to 2003 [29]. There are several potential factors contributing to higher exposure case rates in rural areas, including more employment in resource-based and industrial occupations and Aboriginal communities where substance abuse has been attributed to multi-faceted social and economic challenges [30]. Further characterization of the cases in rural areas would provide more insight into these factors. 


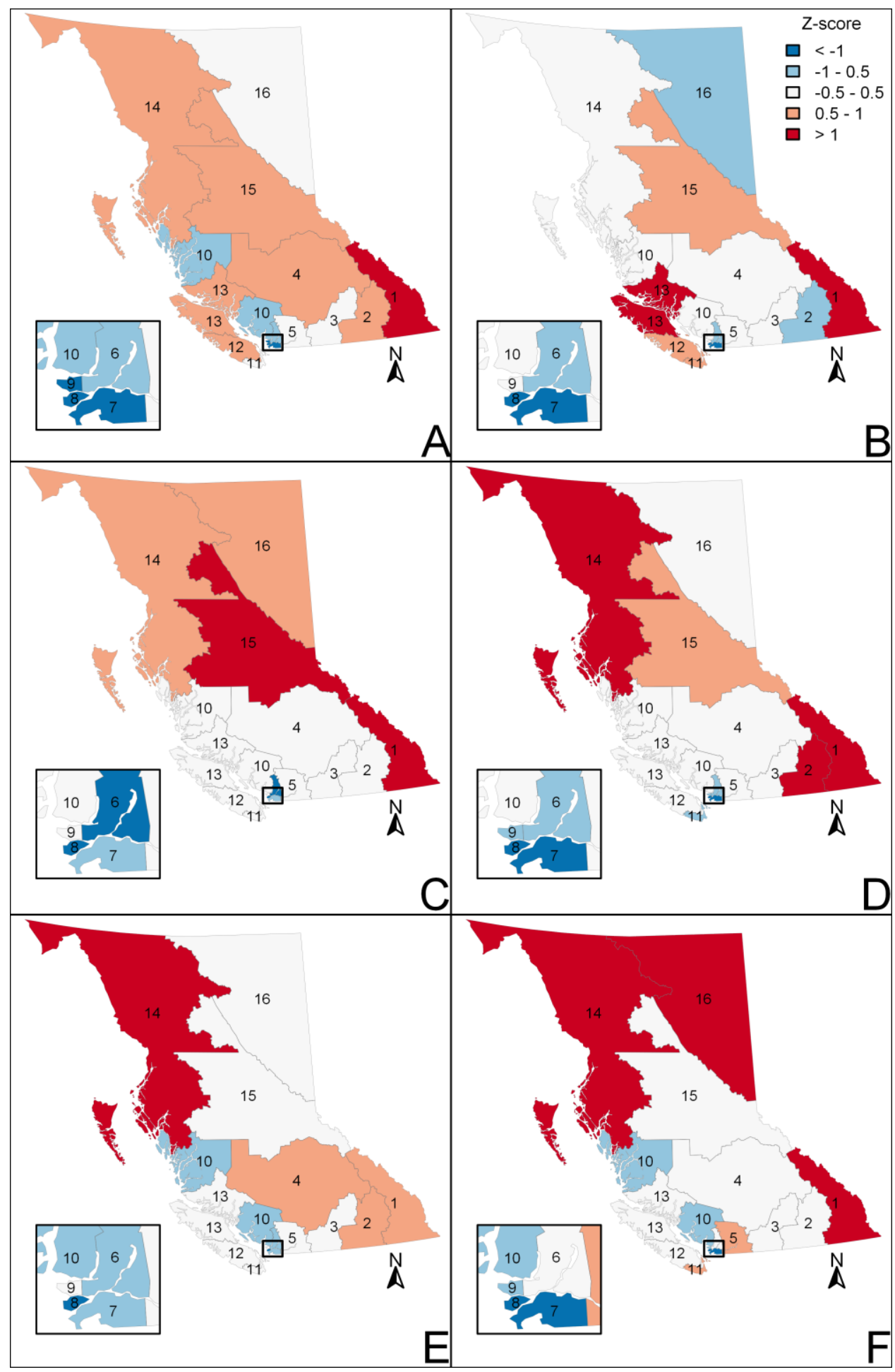

Figure 3: Age-specific human exposure case rate Z-scores by Health Service Delivery Area A: children 5 years of age and under; B: children 6-12 years; C: teens 13-19 years; D: adults 2039 years; E: adults 40-69 years; and F: seniors 70 years of age or older. 


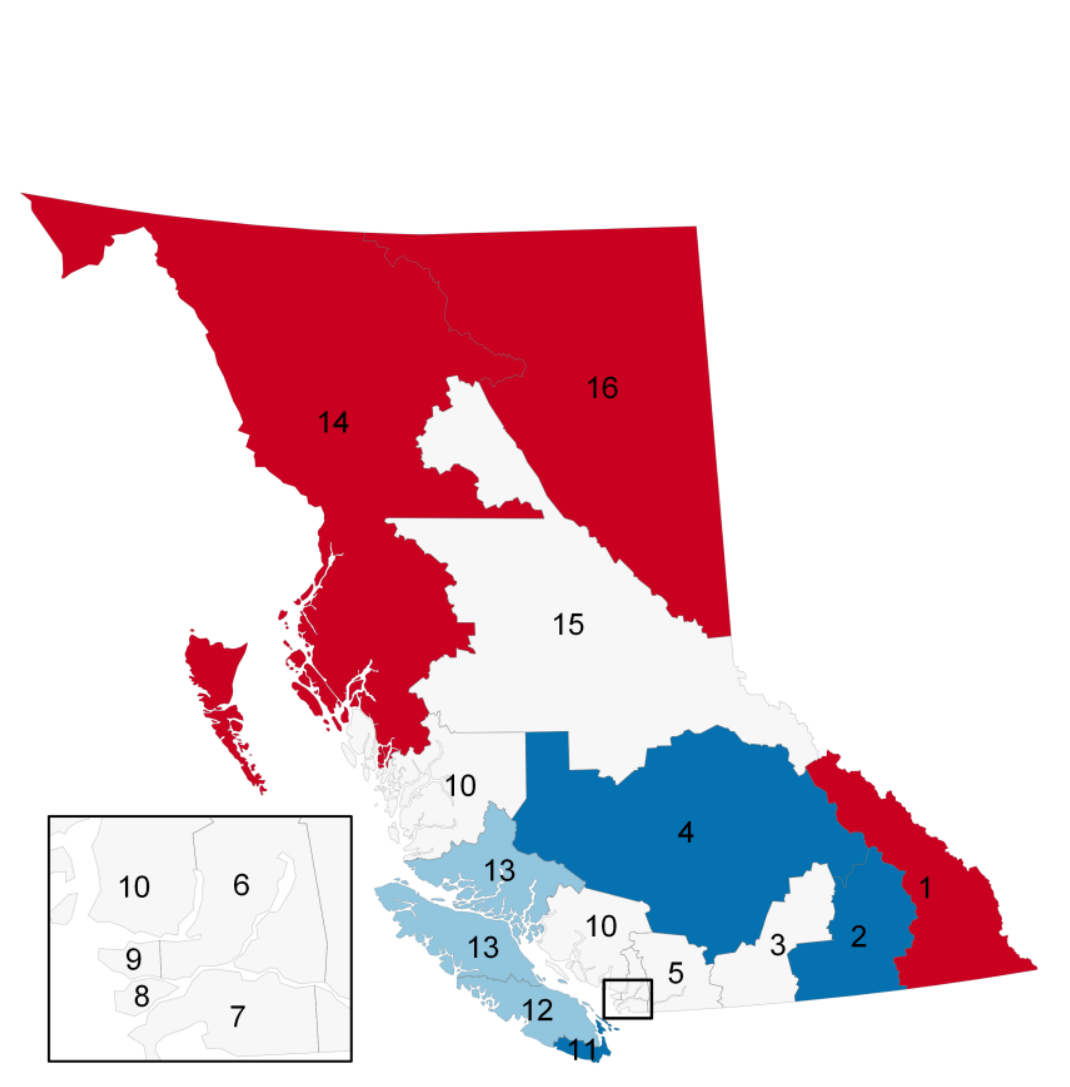

Pharmaceutical exposures

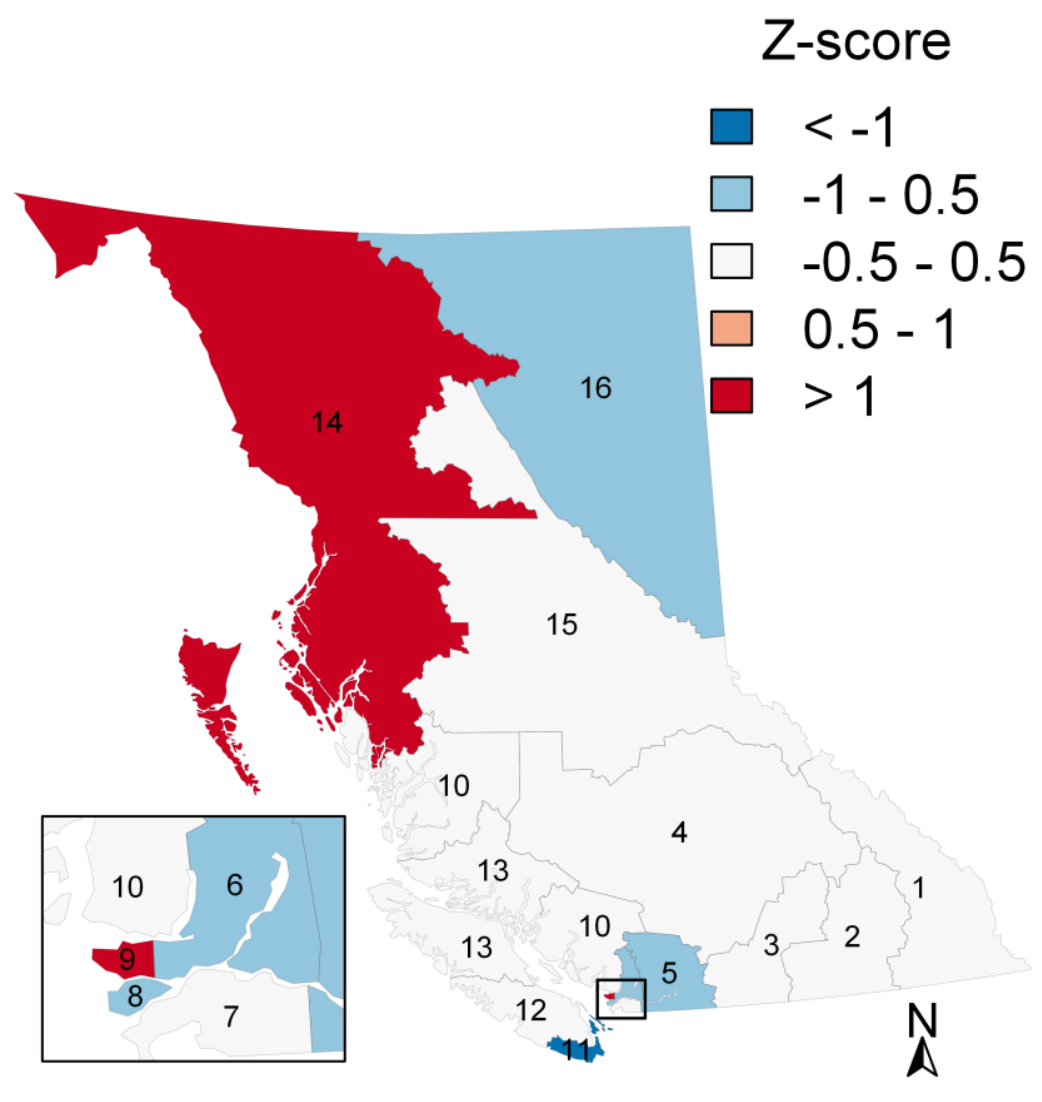

Severe outcomes

Figure 4: The percentage of cases that had a pharmaceutical substance as the primary exposure and the percentage of cases that had a severe medical outcome as Z-scores by Health Service Delivery Area 

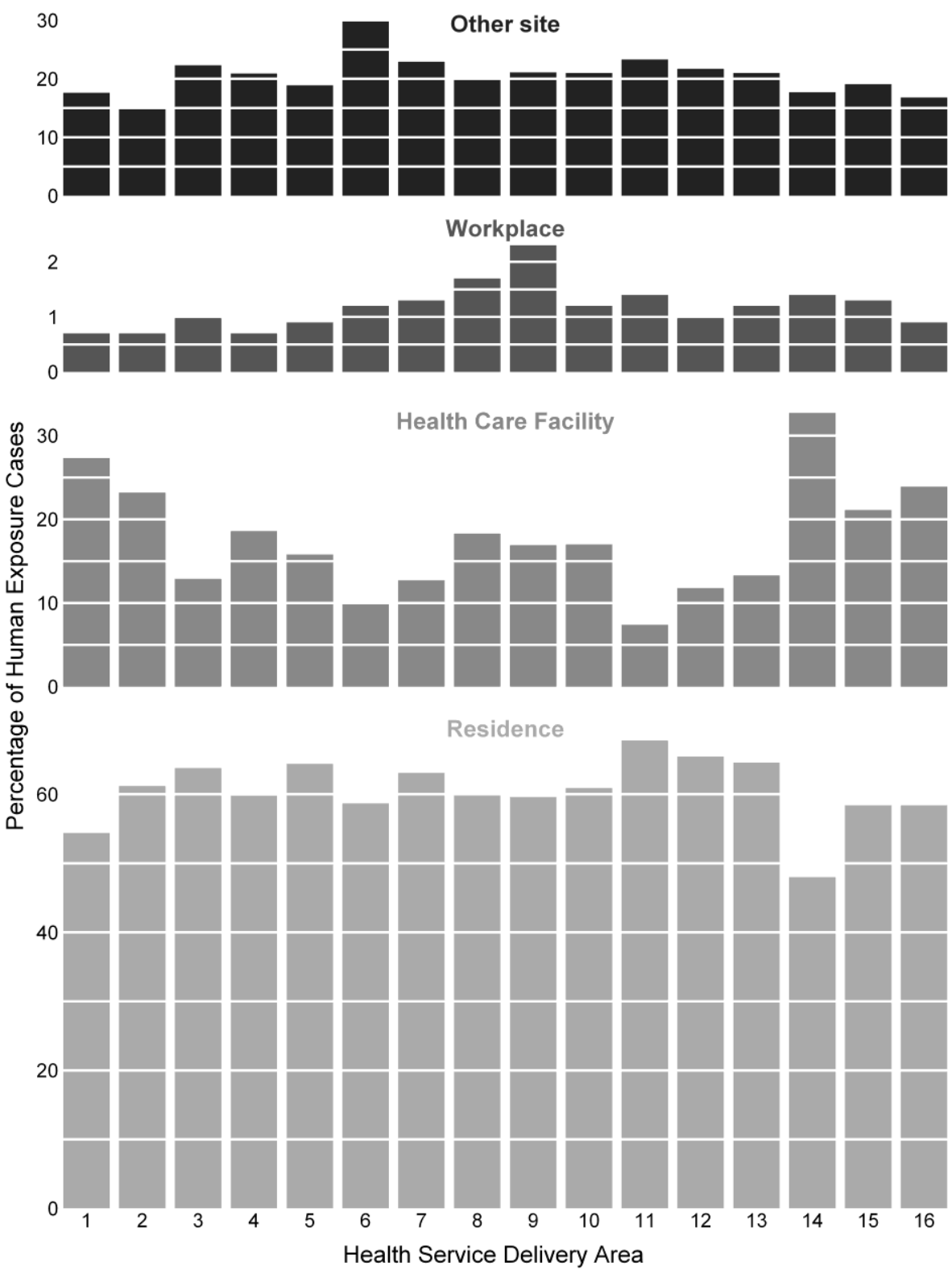

Figure 5: Caller site by Health Service Delivery Area for 2012 \& 2013

Higher case rates in rural HSDAs could also reflect higher PCC awareness and use. Emergency rooms and other health care facilities in remote communities tend to be small, isolated, and resource-limited, making complicated poisoning incidents particularly challenging to manage. Our analysis found higher proportions of calls originating from health care facilities in the more sparsely populated HSDAs (Figure 5), suggesting that staff at rural health care facilities rely on DPIC services more often than those in urban areas. Furthermore, patients must travel longer distances to access primary care in rural/remote areas, so these patients may be more likely to contact the PCC before seeking care. Comparing case rates from DPIC data with rates of poisonings derived from current $\mathrm{BC}$ administrative health data will help to determine whether rates reflect true incidence versus PCC awareness and utilization. 
Our results show higher percentages of cases involving a pharmaceutical substance in several of the primarily rural northern and eastern HSDAs compared with other parts of the province. Pharmaceutical exposures are of interest for several reasons. Firstly, per capita expenditures for prescription drugs in BC increased by 10-13\% each year from 1996-2003, driven mainly by increased use, and two thirds of BC residents filled at least one prescription in 2006 [31]. With increased use, pharmaceuticals become more present in the environment and opportunities for accidents and abuse increase. Pharmaceutical poisonings in children continue to be a public health issue despite prevention efforts in recent decades. Calls to US PCCs regarding pharmaceutical poisonings in children 5 years of age and younger increased from 2001-2008 [32]. Human exposure case rates for children 5 years of age and younger in East Kootenay were the highest in the province. This HSDA also had a higher percentage of pharmaceutical exposures. Further characterization of these cases could potentially inform pediatric poisoning prevention policies. Finally, pharmaceutical exposures are of interest because they relate to prescription drug abuse. There are minimal statistics on the extent of this issue in BC. A survey of grade 7-12 public school students found a statistically significant increase in the proportion of students who had ever tried prescription pills without a doctor's consent from $9 \%$ in 2003 to $15 \%$ in 2008 [33]. In the context of the northern and eastern regions of BC, a factor that may be linked to prescription drug abuse is the prevalence of industrial camps, at which workers for remote mining, oil and gas, or forestry operations live and work, and problems with substance abuse among workers are common [34]. The Northwest HSDA had a higher percentage of cases involving pharmaceutical exposures and a higher percentage of cases with a severe outcome; however, this was not true for other HSDAs, suggesting that other factors affect severity of outcome.

\section{Limitations}

The use of PCC data is limited by a number of factors. Exposures are often self-reported and do not necessarily represent true poisoning incidents. Exposures that present directly to a health care facility will not be included unless healthcare staff consult the PCC. DPIC case data can be incomplete depending on the nature of the call, the precision of the DPIC specialist taking the call, and the willingness of the caller to provide information. There are also some limitations specific to DPIC data. For instance, the default behaviour of the VDLE system around postal codes may affect data quality. Quality assurance and control systems are continuously updated to address these ongoing issues.

Future work will involve further spatial analysis of the case data, and development of surveillance systems for specific exposures and/or outcomes. As with the US National Poison Data System [19], a surveillance system using DPIC data could detect anomalies by comparing call volumes to defined baseline rates. For example, DPIC is exploring methods to automatically extract, analyse, and report on data related to carbon monoxide poisonings.

\section{Conclusion}

This study examined spatial differences in the rates of human exposure cases from DPIC. Rates are generally higher in the rural HSDAs in the north and east of the province and lower in the urban HSDAs of the southern coastal region. Considering these results alongside contextual factors, such as the geography of $\mathrm{BC}$ and diversity of its population, informs further investigation and action. We suggest: addressing cultural and/or language barriers to accessing DPIC services; 
further characterizing cases in the rural health regions to identify factors contributing to higher rates; linking DPIC data with other sources of administrative health data to assess the extent to which DPIC case rates reflect true poisoning incidence; and developing public health surveillance systems for severe poisoning events in $\mathrm{BC}$.

\section{Acknowledgements}

The authors thank Dennis Leong and Victoria Wan for accessing and managing the data, and all of the staff at DPIC for contributing to data collection and sharing their experiences. We also thank our reviewers for helping to improve this work.

\section{Financial Disclosure}

None.

\section{Competing Interests}

None.

\section{References}

1. Land and freshwater area, by province and territory [Internet].: Statistics Canada; 2005 [updated 2005-02-01. Available from: http://www.statcan.gc.ca/tables-tableaux/sumsom/101/cst01/phys01-eng.htm.

2. Population and dwelling counts, for Canada, provinces and territories, census metropolitan areas and census agglomerations, 2011 and 2006 censuses [Internet].: Statistics Canada; 2013 [updated 2013-01-30. Available from: http://www12.statcan.gc.ca/censusrecensement/2011/dp-pd/hlt-fst/pd-pl/Select-GeoChoix.cfm?LANG=Eng\&T $=202 \& G K=P R \& R P P=50$.

3. Visible minority groups, percentage distribution, for Canada, provinces and territories 201\% sample data [Internet].: Statistics Canada; 2010 [updated 2010-10-06. Available from: http://www12.statcan.ca/census-recensement/2006/dp-pd/hlt/97-

562/pages/page.cfm?Lang $=\mathrm{E} \& \mathrm{GeO}=\mathrm{PR} \& \mathrm{Code}=01 \&$ Table $=1 \&$ Data $=$ Dist $\&$ StartRec $=1 \&$ Sort $=2 \&$ Display $=$ Page.

4. Aboriginal identity population by age groups, median age and sex, percentage distribution for both sexes, for Canada, provinces and territories - 20\\% sample data [Internet].: Statistics Canada; 2010 [updated 2010-10-06. Available from: http://www12.statcan.ca/censusrecensement/2006/dp-pd/hlt/97-

558/pages $/$ page. cfm Lang $=\mathrm{E} \& \mathrm{Geo}=\mathrm{PR} \&$ Code $=01 \&$ Table $=1 \&$ Data $=$ Dist $\&$ Sex $=1 \&$ Age $=1 \&$ $\underline{\text { StartRec}}=1 \&$ Sort=2\&Display=Page.

5. McGrail K, Schaub P, Black C. British Columbia health atlas, 2nd edition. Vancouver, Canada: Centre for Health Services and Policy Research; 2004.

6. Zaloshnja E, Miller T, Jones P, Litovitz T, Coben J, et al. 2008. The impact of poison control centers on poisoning-related visits to EDs--United States, 2003. Am J Emerg Med. 26(3), 310-15. PubMed http://dx.doi.org/10.1016/j.ajem.2007.10.014 
7. Vassilev ZP, Marcus SM. 2007. The impact of a poison control center on the length of hospital stay for patients with poisoning. J Toxicol Environ Health A. 70(2), 107-10. PubMed http://dx.doi.org/10.1080/15287390600755042

8. Galvão TF, Silva MT, Silva CD, Barotto AM, Gavioli IL, et al. 2011. Impact of a poison control center on the length of hospital stay of poisoned patients: Retrospective cohort. Sao Paulo Med J. 129(1), 23-29. PubMed http://dx.doi.org/10.1590/S1516-31802011000100005

9. Galvao TF, Silva EN, Silva MT, Bronstein AC, Pereira MG. 2012. Economic evaluation of poison centers: A systematic review. Int J Technol Assess Health Care. 28(2), 86-92. PubMed http://dx.doi.org/10.1017/S0266462312000116

10. Liang S, Friedman LS. 2011. Analysis of suspected suicides using poison center data. Arch Suicide Res. 15(3), 185-94. PubMed http://dx.doi.org/10.1080/13811118.2011.589674

11. Smith MY, Irish W, Wang J, Haddox JD, Dart RC. 2008. Detecting signals of opioid analgesic abuse: Application of a spatial mixed effect poisson regression model using data from a network of poison control centers. Pharmacoepidemiol Drug Saf. 17(11), 1050-59. $\underline{\text { PubMed http://dx.doi.org/10.1002/pds.1658 }}$

12. Sudakin D, Power LE. 2009. Regional and temporal variation in methamphetamine-related incidents: Applications of spatial and temporal scan statistics. Clin Toxicol (Phila). 47(3), 243-47. PubMed http://dx.doi.org/10.1080/15563650802516160

13. Marsolek MR, White NC, Litovitz TL. 2010. Inhalant abuse: Monitoring trends by using poison control data, 1993-2008. Pediatrics. 125(5), 906-13. $\underline{\text { PubMed }}$ http://dx.doi.org/10.1542/peds.2009-2080

14. Sudakin DL, Horowitz Z, Giffin S. 2002. Regional variation in the incidence of symptomatic pesticide exposures: Applications of geographic information systems. $J$ Toxicol Clin Toxicol. 40(6), 767-73. PubMed http://dx.doi.org/10.1081/CLT-120015837

15. Sudakin DL, Power LE. 2007. Organophosphate exposures in the United States: A longitudinal analysis of incidents reported to poison centers. J Toxicol Environ Health A. 70(2), 141-47. PubMed http://dx.doi.org/10.1080/15287390600755224

16. Power LE, Sudakin DL. 2007. Pyrethrin and pyrethroid exposures in the United States: A longitudinal analysis of incidents reported to poison centers. J Med Toxicol. 3(3), 94-99. PubMed http://dx.doi.org/10.1007/BF03160917

17. Sudakin DL, Power LE. 2009. Regional variation in the severity of pesticide exposure outcomes: Applications of geographic information systems and spatial scan statistics. Clin Toxicol (Phila). 47(3), 248-52. PubMed http://dx.doi.org/10.1080/15563650802646694

18. Durigon M, Elliott C, Purssell R, Kosatsky T. Canadian poison control centres: Preliminary assessment of their potential as a resource for public health surveillance. Clin Toxicol. 2013 11/01; 2013/11;51(9):886-91.

19. Wolkin AF, Martin CA, Law RK, Schier JG, Bronstein AC. Using poison center data for national public health surveillance for chemical and poison exposure and associated illness. Ann Emerg Med. 2012 1;59(1):56-61.

20. Population estimates [Internet].: The Province of British Columbia; 2011. Available from: http://www.bcstats.gov.bc.ca/StatisticsBySubject/Demography/PopulationEstimates.aspx. 
21. R Development Core Team. R: A language and environment for statistical computing. 2012.

22. Fay MP, Feuer EJ. 1997. Confidence intervals for directly standardized rates: A method based on the gamma distribution. Stat Med. 16(7), 791-801. PubMed http://dx.doi.org/10.1002/(SICI)1097-0258(19970415)16:7<791::AID-SIM500>3.0.CO;2-\#

23. American Association of Poison Control Centers. National poison data system reference manual. Alexandria, Virginia, USA: 2009.

24. Litovitz T, Benson BE, Youniss J, Metz E. 2010. Determinants of U.S. poison center utilization. Clin Toxicol (Phila). 48(5), 449-57. http://dx.doi.org/10.3109/15563651003757947

25. Mowry JB, Spyker DA, Cantilena LR, Jr, Bailey JE, Ford M. 2013. 2012 annual report of the American Association of Poison Control Centers' National Poison Data System (NPDS):

30th annual report. Clin Toxicol (Phila). 51(10), 949-1229. $\quad$ PubMed http://dx.doi.org/10.3109/15563650.2013.863906

26. Richmond health service delivery area, British Columbia (Code5931) (table). 2006 community profiles. 2006 census. Statistics Canada catalogue no. 92-591-XWE. [Internet].; 2007 [updated 2007-03-13. Available from: http://www12.statcan.gc.ca/censusrecensement/2006/dp-pd/prof/92-591/index.cfm?Lang=E.

27. Rajabali F, Han G, Artes S, Smith D, Brussoni M, et al. Unintentional injuries in British Columbia: Trends and patterns among children and youth. Vancouver, Canada: BC Injury Research and Prevention Unit; 2005.

28. Soubhi H, Lisonkova S, Rajabali F, Tufts C, Raina P. Unintentional injuries in British Columbia: Trends and patterns among adults and seniors 1987-1998. Vancouver, Canada: BC Injury Research and Prevention Unit; 2001.

29. Han G, Turcotte K, Jivani K, Babul S, Pike I. Poisonings in British Columbia 2000-2005. Vancouver, Canada: BC Injury Research and Prevention Unit; 2009.

30. Wesley-Esquimaux CC, Smolewski M. Historic trauma and aboriginal healing. Ottawa, Canada: The Aboriginal Healing Foundation; 2004.

31. Morgan S, Cunningham C, Hanley G, Mooney D. The British Columbia Rx atlas, 2nd edition. Vancouver, Canada: Centre for Health Services and Policy Research; 2009.

32. Bond GR, Woodward RW, Ho M. The growing impact of pediatric pharmaceutical poisoning. J Pediatr. 2012 Feb;160(2):265,270.e1.

33. Stewart D, Vallance K, Stockwell T, Reimer B, Smith A, et al. Adolescent substance use and related harms in British Columbia. Victoria, Canada: Centre for Addictions Research of BC; 2009.

34. Northern Health. Understanding the state of industrial camps in northern BC. Prince George, Canada: Northern Health; 2012. 


\section{Supplementary Material}

Table S1A: Age-Specific Case Rates per 1,000 person-years, 95\% Confidence Intervals, and Z-scores for 0-5, 6-12, and 13-19 years for 2012-2013

\begin{tabular}{|c|c|c|c|c|c|c|c|c|c|}
\hline Health Service Delivery Area & $\begin{array}{l}\text { Case } \\
\text { Rate } \\
(0-5 \\
\text { years })\end{array}$ & $\begin{array}{l}95 \% \\
\text { Confidence } \\
\text { Interval } \\
\text { (Lower, } \\
\text { Upper) }\end{array}$ & Z-score & $\begin{array}{l}\text { Case } \\
\text { Rate } \\
\text { (6-12 } \\
\text { years) }\end{array}$ & \begin{tabular}{|l|}
$95 \%$ \\
Confidence \\
Interval \\
(Lower, \\
Upper)
\end{tabular} & Z-score & $\begin{array}{l}\text { Case } \\
\text { Rate } \\
(13-19 \\
\text { years })\end{array}$ & \begin{tabular}{|l|}
$95 \%$ \\
Confidence \\
Interval \\
(Lower, \\
Upper)
\end{tabular} & Z-score \\
\hline East Kootenay (\#1) & 57.4 & $52.6,62.2$ & 1.08 & 5.2 & $3.9,6.6$ & 1.60 & 6.2 & $4.8,7.6$ & 1.24 \\
\hline Kootenay Boundary (\#2) & 55.3 & $50.1,60.4$ & 0.89 & 3.4 & $2.3,4.5$ & -0.60 & 5.1 & $3.9,6.4$ & 0.34 \\
\hline Okanagan (\#3) & 47.1 & $44.9,49.4$ & 0.18 & 4.0 & $3.4,4.6$ & 0.13 & 4.4 & $3.9,5.0$ & -0.22 \\
\hline Thompson Cariboo Shuswap (\#4) & 53.9 & $51.0,56.8$ & 0.77 & 4.1 & $3.4,4.8$ & 0.25 & 4.6 & $3.9,5.3$ & -0.06 \\
\hline Fraser East (\#5) & 47.0 & $45.0,49.1$ & 0.17 & 4.0 & $3.4,4.6$ & 0.13 & 4.9 & $4.3,5.5$ & 0.18 \\
\hline Fraser North (\#6) & 35.5 & $34.1,36.8$ & -0.84 & 3.1 & $2.7,3.5$ & -0.97 & 3.2 & $2.8,3.5$ & -1.19 \\
\hline Fraser South (\#7) & 30.1 & $29.0,31.1$ & -1.31 & 2.7 & $2.4,3.0$ & -1.46 & 3.6 & $3.3,3.9$ & -0.87 \\
\hline Richmond (\#8) & 18.4 & $16.6,20.3$ & -2.34 & 2.4 & $1.8,2.9$ & -1.83 & 2.0 & $1.5,2.4$ & -2.17 \\
\hline Vancouver (\#9) & 30.2 & $28.9,31.6$ & -1.30 & 3.5 & $3.0,3.9$ & -0.48 & 5.2 & $4.7,5.7$ & 0.43 \\
\hline North Shore/Coast Garibaldi (\#10) & 37.3 & $35.2,39.5$ & -0.68 & 4.1 & $3.5,4.7$ & 0.25 & 4.1 & $3.6,4.7$ & -0.47 \\
\hline South Vancouver Island (\#11) & 46.9 & $44.7,49.1$ & 0.16 & 4.5 & $3.9,5.2$ & 0.74 & 4.1 & $3.6,4.7$ & -0.47 \\
\hline Central Vancouver Island (\#12) & 54.2 & $51.4,56.9$ & 0.80 & 4.4 & $3.7,5.1$ & 0.62 & 4.1 & $3.5,4.7$ & -0.47 \\
\hline North Vancouver Island (\#13) & 53.9 & $50.0,57.9$ & 0.77 & 5.3 & $4.2,6.4$ & 1.72 & 4.7 & $3.8,5.7$ & 0.02 \\
\hline Northwest (\#14) & 52.4 & $49.7,56.8$ & 0.64 & 4.1 & $3.0,5.2$ & 0.25 & 5.7 & $4.5,7.0$ & 0.83 \\
\hline Northern Interior (\#15) & 54.1 & $50.9,57.4$ & 0.79 & 4.4 & $3.6,5.3$ & 0.62 & 7.2 & $6.2,8.2$ & 2.04 \\
\hline Northeast (\#16) & 47.9 & $44.0,51.8$ & 0.25 & 3.1 & $2.1,4.0$ & -0.97 & 5.7 & $4.4,7.0$ & 0.83 \\
\hline
\end{tabular}


Table S1B. Age-Specific Case Rates per 1,000 person-years, 95\% Confidence Intervals, and Z-scores for 20-39, 40-69, and 70 plus years for 2012-2013

\begin{tabular}{|c|c|c|c|c|c|c|c|c|c|}
\hline Health Service Delivery Area & \begin{tabular}{|l|} 
Case \\
Rate \\
$(\mathbf{2 0 - 3 9}$ \\
years $)$
\end{tabular} & \begin{tabular}{|l|}
$95 \%$ \\
Confidence \\
Interval \\
(Lower, \\
Upper) \\
\end{tabular} & Z-score & \begin{tabular}{|l|} 
Case \\
Rate \\
(40-69 \\
years)
\end{tabular} & $\begin{array}{l}95 \% \\
\text { Confidence } \\
\text { Interval } \\
\text { (Lower, } \\
\text { Upper) }\end{array}$ & Z-score & \begin{tabular}{|l} 
Case \\
Rate \\
(70 plus \\
years)
\end{tabular} & $\begin{array}{l}95 \% \\
\text { Confidence } \\
\text { Interval } \\
\text { (Lower, } \\
\text { Upper) }\end{array}$ & Z-score \\
\hline East Kootenay (\#1) & 3.9 & $3.2,4.6$ & 1.26 & 1.8 & $1.5,2.1$ & 0.84 & 3.1 & $2.3,3.9$ & 1.95 \\
\hline Kootenay Boundary (\#2) & 4.1 & $3.4,4.8$ & 1.47 & 1.8 & $1.5,2.1$ & 0.84 & 2.2 & $1.6,2.8$ & -0.13 \\
\hline Okanagan (\#3) & 2.5 & $2.3,2.8$ & -0.27 & 1.3 & $1.2,1.4$ & -0.38 & 2.2 & $1.9,2.5$ & -0.13 \\
\hline Thompson Cariboo Shuswap (\#4) & 3.0 & $2.6,3.3$ & 0.27 & 1.7 & $1.5,1.9$ & 0.60 & 2.3 & $1.9,2.7$ & 0.10 \\
\hline Fraser East (\#5) & 2.5 & $2.2,2.7$ & -0.27 & 1.5 & $1.3,1.7$ & 0.11 & 2.5 & $2.1,2.9$ & 0.56 \\
\hline Fraser North (\#6) & 1.9 & $1.7,2.0$ & -0.93 & 1.2 & $1.1,1.3$ & -0.63 & 2.2 & $1.9,2.4$ & -0.13 \\
\hline Fraser South (\#7) & 1.8 & $1.6,1.9$ & -1.04 & 1.2 & $1.1,1.3$ & -0.63 & 1.6 & $1.4,1.8$ & -1.51 \\
\hline Richmond (\#8) & 1.3 & $1.1,1.5$ & -1.58 & 0.6 & $0.5,0.7$ & -2.10 & 1.3 & $0.9,1.7$ & -2.21 \\
\hline Vancouver (\#9) & 2.2 & $2.1,2.4$ & -0.60 & 1.6 & $1.5,1.8$ & 0.35 & 2.0 & $1.8,2.3$ & -0.59 \\
\hline North Shore/Coast Garibaldi (\#10) & 2.3 & $2.1,2.6$ & -0.49 & 1.1 & $1.0,1.2$ & -0.87 & 2.0 & $1.6,2.3$ & -0.59 \\
\hline South Vancouver Island (\#11) & 2.1 & $1.9,2.3$ & -0.71 & 1.3 & $1.2,1.5$ & -0.38 & 2.6 & $2.3,3.0$ & 0.79 \\
\hline Central Vancouver Island (\#12) & 2.7 & $2.4,3.0$ & -0.05 & 1.3 & $1.2,1.5$ & -0.38 & 2.2 & $1.9,2.6$ & -0.13 \\
\hline North Vancouver Island (\#13) & 2.6 & $2.1,3.1$ & -0.16 & 1.6 & $1.4,1.9$ & 0.35 & 2.1 & $1.6,2.6$ & -0.36 \\
\hline Northwest (\#14) & 4.8 & $4.1,5.5$ & 2.24 & 2.5 & $2.1,2.9$ & 2.56 & 2.7 & $1.7,3.6$ & 1.02 \\
\hline Northern Interior (\#15) & 3.3 & $2.9,3.7$ & 0.60 & 1.4 & $1.2,1.7$ & -0.14 & 2.4 & $1.8,3.1$ & 0.33 \\
\hline Northeast (\#16) & 3.0 & $2.5,3.5$ & 0.27 & 1.4 & $1.1,1.8$ & -0.14 & 2.7 & $1.6,3.9$ & 1.02 \\
\hline
\end{tabular}


Table S2. Case Rates and 95\% Confidence Intervals per 1,000 person-years for Pharmaceutical and Non-pharmaceutical Exposures for 2012-2013

\begin{tabular}{|c|c|c|c|c|c|c|}
\hline Health Service Delivery Area & $\begin{array}{l}\text { Case Rate for } \\
\text { Pharmaceutical } \\
\text { Exposures }\end{array}$ & $\begin{array}{l}95 \% \\
\text { Confidence } \\
\text { Interval } \\
\text { (Lower, } \\
\text { Upper) }\end{array}$ & $\begin{array}{l}\text { Case Rate for } \\
\text { Non- } \\
\text { pharmaceutical } \\
\text { Exposures }\end{array}$ & $\begin{array}{l}95 \% \\
\text { Confidence } \\
\text { Interval } \\
\text { (Lower, } \\
\text { Upper) }\end{array}$ & $\begin{array}{l}\text { Percentage of } \\
\text { Cases with a } \\
\text { Pharmaceutical } \\
\text { Exposure }(\%)\end{array}$ & Z-score \\
\hline East Kootenay (\#1) & 3.6 & $3.3,3.9$ & 4.0 & $3.6,4.3$ & 46.8 & 1.46 \\
\hline Kootenay Boundary (\#2) & 2.8 & $2.5,3.0$ & 4.0 & $3.6,4.3$ & 40.4 & -1.62 \\
\hline Okanagan (\#3) & 2.4 & $2.3,2.5$ & 3.0 & $2.9,3.1$ & 43.6 & -0.08 \\
\hline Thompson Cariboo Shuswap (\#4) & 2.8 & $2.6,2.9$ & 3.8 & $3.6,4.0$ & 41.6 & -1.04 \\
\hline Fraser East (\#5) & 3.0 & $2.9,3.2$ & 3.7 & $3.5,3.8$ & 44.3 & 0.26 \\
\hline Fraser North (\#6) & 2.1 & $2.1,2.2$ & 2.6 & $2.5,2.7$ & 44.6 & 0.40 \\
\hline Fraser South (\#7) & 2.0 & $1.9,2.1$ & 2.5 & $2.4,2.5$ & 44.1 & 0.16 \\
\hline Richmond (\#8) & 1.1 & $1.0,1.2$ & 1.5 & $1.3,1.6$ & 43.0 & -0.37 \\
\hline Vancouver (\#9) & 2.2 & $2.2,2.3$ & 2.7 & $2.6,2.8$ & 44.4 & 0.31 \\
\hline North Shore/Coast Garibaldi (\#10) & 2.1 & $2.0,2.2$ & 2.8 & $2.6,2.9$ & 43.0 & -0.37 \\
\hline South Vancouver Island (\#11) & 2.3 & $2.2,2.4$ & 3.2 & $3.1,3.3$ & 41.3 & -1.19 \\
\hline Central Vancouver Island (\#12) & 2.6 & $2.4,2.7$ & 3.5 & $3.3,3.6$ & 41.9 & -0.90 \\
\hline North Vancouver Island (\#13) & 2.7 & $2.5,2.9$ & 3.7 & $3.4,3.9$ & 42.1 & -0.80 \\
\hline Northwest (\#14) & 4.1 & $3.8,4.4$ & 4.4 & $4.1,4.8$ & 47.3 & 1.70 \\
\hline Northern Interior (\#15) & 3.4 & $3.2,3.6$ & 4.1 & $3.8,4.3$ & 44.7 & 0.45 \\
\hline Northeast (\#16) & 3.7 & $3.4,4.0$ & 4.0 & $3.7,4.4$ & 47.1 & 1.61 \\
\hline
\end{tabular}


Table S3. Case Rates and 95\% Confidence Intervals per 1,000 person-years for Cases with Severe and Mild Medical Outcomes for 2012-2013

\begin{tabular}{|c|c|c|c|c|c|c|}
\hline Health Service Delivery Area & $\begin{array}{l}\text { Case Rate for } \\
\text { Severe } \\
\text { Outcome }\end{array}$ & $\begin{array}{l}95 \% \\
\text { Confidence } \\
\text { Interval } \\
\text { (Lower, } \\
\text { Upper) }\end{array}$ & $\begin{array}{l}\text { Case Rate for } \\
\text { Mild Outcome }\end{array}$ & $\begin{array}{l}95 \% \\
\text { Confidence } \\
\text { Interval } \\
\text { (Lower, } \\
\text { Upper) }\end{array}$ & $\begin{array}{l}\text { Percentage of } \\
\text { Cases with a } \\
\text { Severe } \\
\text { Outcome (\%) }\end{array}$ & Z-score \\
\hline East Kootenay (\#1) & 1.4 & $1.2,1.6$ & 6.3 & $5.9,6.7$ & 18.0 & 0.39 \\
\hline Kootenay Boundary (\#2) & 1.2 & $1.1,1.4$ & 5.6 & $5.2,6.0$ & 18.1 & 0.45 \\
\hline Okanagan (\#3) & 1.0 & $0.9,1.0$ & 4.6 & $4.4,4.7$ & 17.3 & -0.01 \\
\hline Thompson Cariboo Shuswap (\#4) & 1.2 & $1.1,1.3$ & 5.5 & $5.3,5.8$ & 17.3 & -0.01 \\
\hline Fraser East (\#5) & 1.1 & $1.0,1.2$ & 5.7 & $5.5,5.9$ & 16.1 & -0.71 \\
\hline Fraser North (\#6) & 0.8 & $0.7,0.8$ & 4.1 & $3.9,4.2$ & 15.8 & -0.88 \\
\hline Fraser South (\#7) & 0.7 & $0.7,0.8$ & 3.8 & $3.7,3.9$ & 16.5 & -0.48 \\
\hline Richmond (\#8) & 0.4 & $0.4,0.5$ & 2.2 & $2.0,2.3$ & 16.4 & -0.53 \\
\hline Vancouver (\#9) & 1.0 & $1.0,1.1$ & 4.0 & $3.9,4.1$ & 20.3 & 1.72 \\
\hline North Shore/Coast Garibaldi (\#10) & 0.8 & $0.7,0.9$ & 4.1 & $4.0,4.3$ & 16.6 & -0.42 \\
\hline South Vancouver Island (\#11) & 0.8 & $0.8,0.9$ & 4.7 & $4.6,4.9$ & 14.7 & -1.52 \\
\hline Central Vancouver Island (\#12) & 1.0 & $0.9,1.1$ & 5.1 & $4.9,5.3$ & 16.8 & -0.30 \\
\hline North Vancouver Island (\#13) & 1.2 & $1.0,1.3$ & 5.3 & $5.0,5.6$ & 17.9 & 0.33 \\
\hline Northwest (\#14) & 1.9 & $1.7,2.1$ & 6.8 & $6.4,7.2$ & 21.8 & 2.59 \\
\hline Northern Interior (\#15) & 1.3 & $1.2,1.5$ & 6.3 & $6.0,6.6$ & 17.5 & 0.10 \\
\hline Northeast (\#16) & 1.3 & $1.1,1.5$ & 6.6 & $6.2,7.0$ & 16.1 & -0.71 \\
\hline
\end{tabular}

